$16^{\text {th }}$ International Conference on

AEROSPACE SCIENCES \& AVIATION TECHNOLOGY,

ASAT - 16 - May 26 - 28, 2015, E-Mail: asat@ mtc.edu.eg

Military Technical College, Kobry Elkobbah, Cairo, Egypt

Tel : +(202) 24025292 - 24036138, Fax: +(202) 22621908

\title{
Identification and Optimal PI Control of an Electrostatic Precipitator
}

\author{
O. H. Abdalla* , S. M. Sharaf ${ }^{\dagger}$ and H. F. Feshara ${ }^{\ddagger}$
}

\begin{abstract}
This paper describes the identification and design of optimal Proportional plus Integral (PI) control system for a high voltage unit of an electrostatic precipitator (ESP) filter of a real cement kiln. The unbiased recursive least-squares algorithm is used to identify a linear discrete-time state-space model of the system based on state and measurements that were recorded during subjecting the system to a pseudo random binary sequence superimposed on its input. The state and input variables have been measured by using a dedicated electronic interface system especially designed for this purpose. Based on the identified model an optimal PI controller is designed by minimizing a quadratic performance index using dynamic programming algorithm. The controller is implemented on the real ESP filter and practical tests are presented to show the system performance.
\end{abstract}

Keywords: electrostatic precipitator, model identification, optimal control, cement kiln

\section{Introduction}

Electrostatic precipitators (ESP) are widely used in various industries and premises to clean air and waste gasses by removing suspended particles using electrostatic forces [1]-[3]. They have found many applications in cement plants [4] and steel industries [5], and also in cleaning indoor air in special buildings such as hospitals and food processing factories. Recent development in plasma ESP is described in [6]. The design of a smart home small scale ESP is described in [7] for the use in biomass furnaces. The development of an ESP for removing Martian atmospheric dust from gas intakes of planetary exploration missions is described in [8].

To operate at high efficiency and low cost, the electrostatic precipitator (ESP) should be tightly and accurately controlled and monitored. A number of controlled high voltage units are normally used in the ESP. These units provide the high voltage required for the precipitator electrodes to generate the electrostatic field through which the gasses to be cleaned are passed. Computer control and monitoring the operation of ESP filters are described in $[9,10]$.

\footnotetext{
*Professor, University of Helwan, Cairo, Egypt, ohabdalla@ieee.org

${ }^{\dagger}$ Professor, University of Helwan, Cairo, Egypt, soliman-sharaf@ hotmail.com

*Engineer, ASEC Environmental Protection Company, Cairo, Egypt, feshara@gmail.com
} 
The objective of this paper is to present identification and optimal proportional plus Integral (PI) controller design for a high voltage unit of a practical ESP in a large cement factory [11]. A state-space model of the high voltage unit of the ESP is obtained from real measurements by using unbiased recursive least square identification. The measured variables are voltages and currents at both low voltage and high voltage sides of the transformer/rectifier power circuit supplying the precipitator filter. The measured signals are interfaced with the computer through a data acquisition card. A triggering circuit has been also designed and implemented to provide the control signals to the thyristors used in the power circuit of the precipitator filter. Based on the identified model, an optimal PI controller is designed by minimizing a quadratic performance index using dynamic programming procedure. The optimal controller is implemented on the ESP of the cement kiln and practical tests of the closed loop control system are presented to show the effectiveness of identification and control design. The paper is organized as follows. Section 2 describes the ESP. Section 3 presents the application of recursive least squares identification to obtain a state space model of the high voltage unit in the ESP. Section 4 presents the results of the system identification. Section 5 describes the design of the optimal PI controller. Section 6 presents the practical implementation and results of the optimal PI controller. Section 7 summarizes the main conclusions.

\section{ESP System Description}

The ESP system of concern is a filter mounted on a cement production rotary kiln inside the National Cement Company, El-Tebbin, Cairo, Egypt [11]. Fig. 1 shows this ESP filter which consists of two parallel precipitators; each has 4 fields.

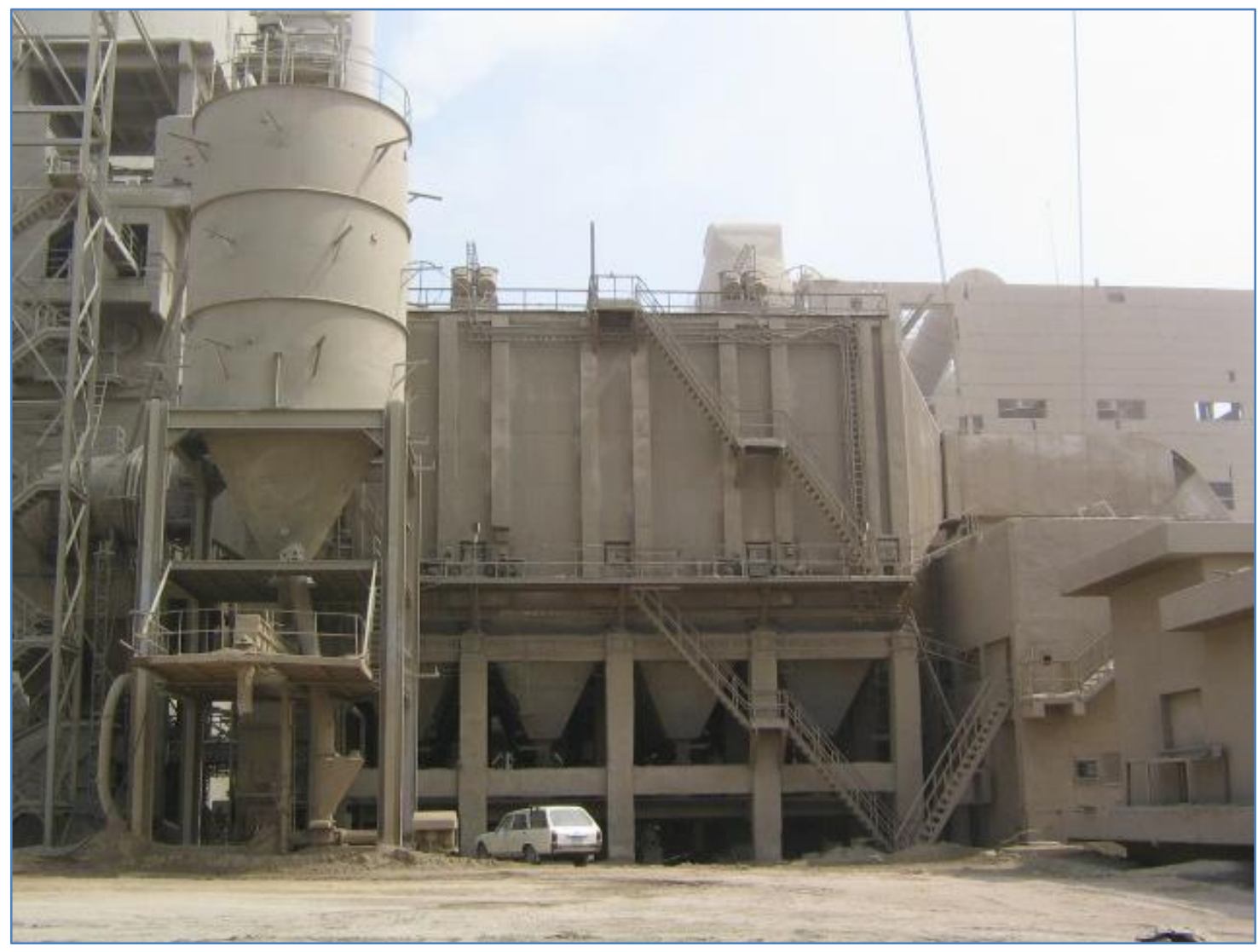

Fig. 1. The ESP in the National Cement Company. 
The waste gas flow capacity is $236047 \mathrm{~m}^{3} /$ hour, and the active cross-section area is $74 \mathrm{~m}^{2}$. The ESP is equipped with 2 fans; each has a $500 \mathrm{~kW}, 6 \mathrm{kV}$ three-phase motor. Each field in the ESP is equipped with a high voltage unit located in a power distribution station beneath the filter. The HV unit consists of a transformer, rectifier bridge, HV connector, and control device. Experiments were made upon the HV unit that supplies the ESP field 8:

- Rated mains $=380 \mathrm{~V}, 50 \mathrm{~Hz}, 248 \mathrm{~A}$.

- Rated output $=50 \mathrm{kV}$ (mean), $80 \mathrm{kV}$ (peak)

- Rated rectified load current $=1000 \mathrm{~mA}$ (mean value)

Fig. 2 shows a schematic diagram of the implemented ESP control system. Four measuring electronic circuits have been designed and built to measure primary voltage, primary current, secondary voltage and secondary current of the HV unit. An electronic firing circuit has been designed and built to provide control signals for back-to-back thyristors which control the HV unit. An interface module is used to connect the measured and firing signals to a computer through ADC and DAC units. Details can be found in [11] and [12].

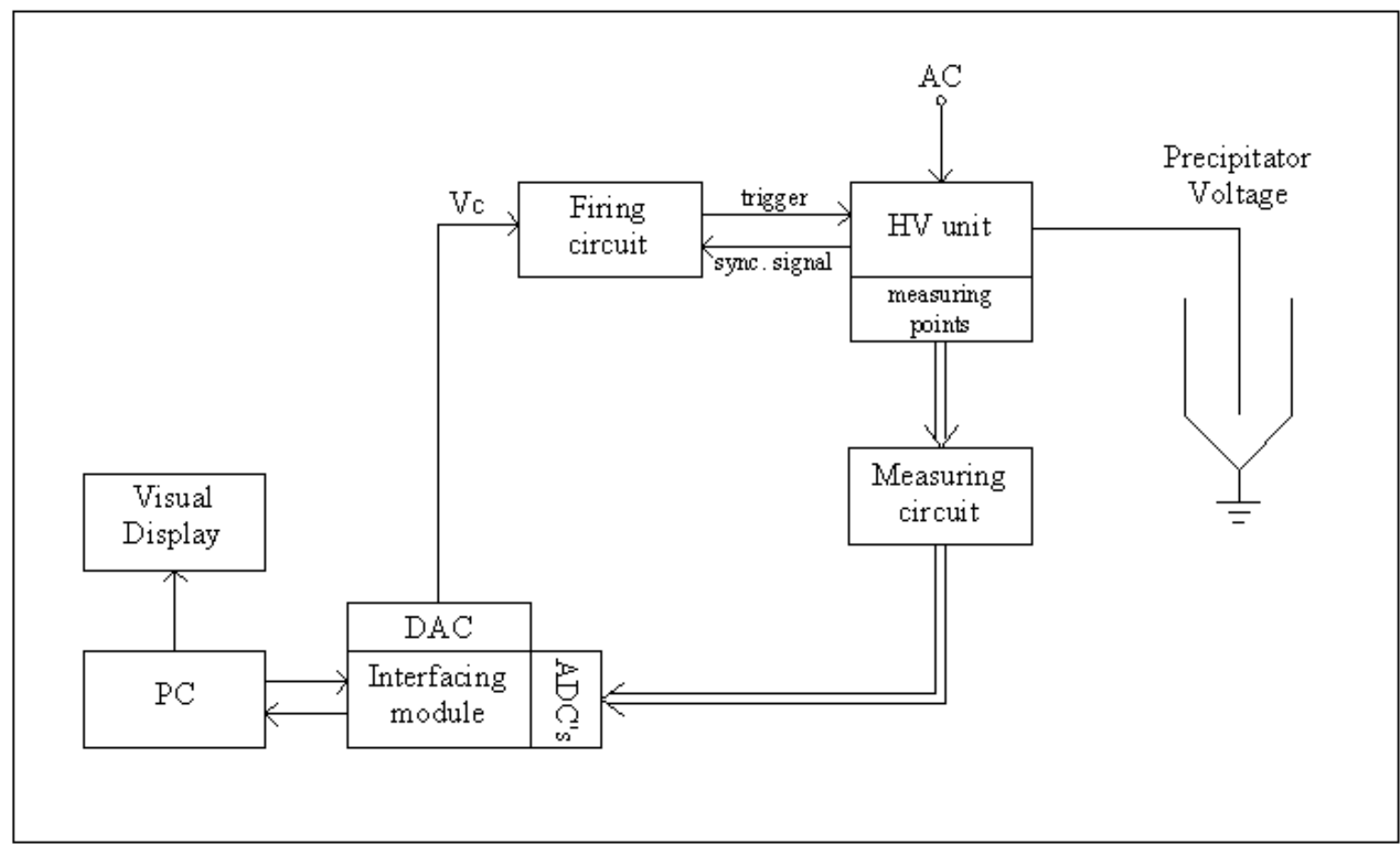

Fig. 2. Schematic diagram of the interfacing system

\section{System Identification}

In order to design controls for a dynamic system it is necessary to obtain a model which will adequately describe the system's behavior. The process of constructing models and estimating the best values of unknown parameters from experimental data is called system identification [13]. In pure science it is aimed to develop models of nature as it is; in control, the control design objectives influences which models are used [14]. In general, system identification is divided into parametric and nonparametric methods [13]. In parametric methods, a system model is assumed, and the identification amounts to an estimation of the model parameters. In nonparametric methods, no assumption is made about the system model, and the identification is used to directly compute the system frequency responses. Nonparametric methods include: correlation analysis, transient-response analysis, and frequency response, Fourier, or spectrum analysis [15]. The design of multivariable controllers is usually based on linear models of the plant dynamics. In the case of a complex nonlinear process, these models are frequently 
obtained by reducing the order of the system equations, and linearizing the equations by considering only small perturbations about a chosen operating condition. This method may not be sufficiently accurate, as it depends on the validity of the original nonlinear model, which must contain various assumptions and approximations, the precision with which the parameters are known, and limitations due to the order reduction and linearization [16].

An alternative is to employ the techniques of parameter identification to seek a linear model directly from the practical plant itself, and this approach is particularly appropriate for digital control schemes. Various methods have been developed [13], and numerous studies and applications appear in the literature [16], [17]; including comparisons of the performance of different algorithms in identifying simulated systems and practical processes.

\subsection{Unbiased Recursive Least Squares Algorithm}

An Unbiased Recursive Least Squares (URLS) identification algorithm is applied to estimate noise-free accurate parameters of a linear model. Unbiased recursive least squares identification algorithm is considered a parametric method and is used to estimate parameters of a discrete state-space model. Previous investigations [17], [18] have shown that a discrete state-space model of a multivariable system may be written as:

$$
X_{k+1}=\Phi X_{k}+\Delta u_{k}
$$

Where $X_{k}(\mathrm{n} \times 1)$ is the state vector at the $\mathrm{k}^{\text {th }}$ sampling instant, and $u_{k}$ is a scalar input. If $\Psi$ is defined as an $[n \times(n+1)]$ parameter matrix, such that:

$$
\Psi=[\Phi \vdots \Delta]
$$

Then $X_{k+1}$ becomes

$$
X_{k+1}=\Psi Z_{k}
$$

Where $Z_{k}$ is the augmented $[(\mathrm{n}+1) \times 1]$ state/input vector defined by:

$$
Z_{k}=\left[X_{k}^{T}: u_{k}\right]^{T}
$$

For estimating the matrices $\Phi$ and $\Delta$, the matrix $(\Psi)$ is to be identified. Let us define an error function which can be computed from $u_{k}$ and $X_{k}$.

$$
\epsilon_{k}=X_{k}-\Psi Z_{k-1}
$$

Where $\epsilon_{k}$ is called the output error which is used to adjust model parameters and thus reduce the output error [13], [19].

The identification methods are based on a minimization of the quadratic cost function $J$ containing the squared errors over the observation period 1 to $\mathrm{N}$. The cost function is

$$
J\left(W_{N}\right)=\frac{1}{N} \sum_{k=1}^{N} \epsilon_{k}^{T} \epsilon_{k}
$$

A good choice for minimization of the cost function is the recursive least-squares algorithm, which guarantees model parameters convergence and absolute stability; however, it may lead to biased estimates of parameters if the input data are corrupted with non-white noise. The amount of bias mainly depends on the ratio between the deterministic part of the measured quantities and the noise level. This limits the applications of the recursive least squares to cases in which it 
is possible to apply sufficiently large disturbances to plant inputs to obtain a satisfactory signal/noise ratio, without adversely affecting plant safety and stability, and the linearity of the identified model [16].

The unbiased recursive least squares approach provides an unbiased estimate of the system parameters [18], [20]. Minimization of the cost function using URLS is described by the following equations:

$\Psi_{k}=\Psi_{k-1}+\Upsilon$

$\Upsilon=\left(X_{k}-\Psi_{k-1} X_{k-1}\right)\left(X_{k-1}^{T} P_{k-1} X_{k-1}\right)^{-1} X_{k-1}^{T} P_{k-1}$

$P_{k}=P_{k-1}-P_{k-1} X_{k-1}\left(X_{k-1}^{T} P_{k-1} X_{k-1}+1\right)^{-1} X_{k-1}^{T} P_{k-1}$

Where:

$X_{k}=\left[V_{k}^{T} \vdots u_{k}\right]^{T}$ and $V_{k}=\Psi X_{k-1}$

$\Psi_{K}$ represents the estimated parameter matrix based on $\mathrm{N}$ sets of measurements [16].

\subsection{High Voltage Unit Identification}

A fourth order discrete state-space model of the high voltage unit is considered in this study, (i.e. $\mathrm{n}=4$ and $\mathrm{m}=1$ ). We define the input $u$ and the state vector $X$ as:

$$
\begin{aligned}
& u=V_{C} \\
& X=\left[\begin{array}{l}
V_{1} \\
I_{1} \\
V_{2} \\
I_{2}
\end{array}\right]
\end{aligned}
$$

Where:

$V_{1}=$ deviation of the primary voltage $(\mathrm{V}$ AC)

$I_{1}=$ deviation of the primary current (A AC)

$V_{2}=$ deviation of the secondary voltage $(\mathrm{kV} \mathrm{DC})$

$I_{2}=$ deviation of the secondary current (mA DC)

$V_{C}=$ controlling voltage that corresponds to thyristors' firing angles

For producing a set of input sample values $\left\{u_{k}\right\}$ and a set of corresponding state sample values $\left\{X_{k}\right\}$ to be used in the URLS algorithm, a pseudo-random binary sequence input is superimposed on the controlling voltage of the firing angle of the thyristors. The PseudoRandom Binary Sequence (PRBS) is a periodic, deterministic input which can be generated using shift registers and Boolean algebra, The PRBS should meet the following requirements [21]:

- To be as short as possible

- Not to take actuators to limits, or exceed move size restriction

- Cause minimum disruption to the controlled variables 
The PRBS is generated by using a seventh-order shift register. The PRBS is superimposed on the controlling voltage $\left(V_{C}\right)$ of the firing circuit. The system states of the primary voltage, primary current, secondary voltage, and secondary current are measured using the developed measuring circuit. This data is stored in a Microsoft Excel file for display and further processing. The system is sampled at $4.16 \mathrm{~ms}$ intervals and one PRBS output is allowed to stand for 25 sampling intervals. The controlling voltage was $6.9 \mathrm{~V}$, and a PRBS was superimposed upon it with a small percentage of $+6 \%$ and $-6 \%$ resulting PRBS limits to be 6.486 Volts and 7.314 Volts.

\section{Results of System Identification}

The operating conditions of the electrostatic precipitator during the experiment were recorded from the central control room and were as follows:

- EP1 inlet temperature $=295^{\circ} \mathrm{C}$

- EP1 outlet temperature $=282{ }^{\circ} \mathrm{C}$

- EP2 inlet temperature $=303{ }^{\circ} \mathrm{C}$

- EP2 outlet temperature $=294{ }^{\circ} \mathrm{C}$

- Temperature of smoke chamber $310{ }^{\circ} \mathrm{C}$

- South fan 50 A, damper opened $80 \%$

- North fan 44 A, damper opened 95\%

- Kiln feed 20 Liter/sec

- Moisture content $37.5 \%$

- HV units readings during the experiment were as follows:

EP1 :

Inlet: TR1 $34 \mathrm{kV} 550 \mathrm{~mA}$, TR2 $31 \mathrm{kV} 260 \mathrm{~mA}$

Outlet: TR3 45 kV 320 mA, TR4 24 kV 540 mA

EP2 :

Inlet: TR1 $32 \mathrm{kV} 520 \mathrm{~mA}$, TR2 $35 \mathrm{kV} 420 \mathrm{~mA}$

Outlet: TR3 $25 \mathrm{kV} 560 \mathrm{~mA}$.

The test results of primary voltage, primary current, secondary voltage and secondary current have been recorded during the experiment. For using the unbiased recursive least squares algorithm, the deviations of the primary voltage, primary current, secondary voltage and secondary current from their initial states are calculated from the data recorded during the experiment.

A MATLAB function is written to estimate the state space matrices $\Phi$ and $\Delta$ from $\mathrm{N}$ input sample values $\left\{u_{k}\right\}$ and a set of corresponding measurable state sample values $\left\{X_{k}\right\}$. Based on equations (7) to (9), the initial values of $\Psi, P$ and $X$ are assumed, then, iterations for evaluating $\Psi$ are done upon $N$ input-output data sequence. The convergence of elements of $\Phi$ and $\Delta$ to stable values during iteration is followed during the recursive estimation process upon the available data.

\subsection{Model Assessment}

The quality of the identified model is assessed by directly comparing the system responses with those of the model at the same PRBS inputs. Fig. 3 shows the real high voltage unit response for primary voltage, primary current, secondary voltage, and secondary current. In addition, the identified model outputs are shown in the figure. Good quality between the real system and identified model response over the test are obtained for all variables. The system parameters $\Phi$ and $\Delta$ are calculated at the above operating conditions and gives the following matrices: 


$$
\begin{aligned}
& \Phi=\left[\begin{array}{rrrr}
0.7299 & -0.0074 & -0.1692 & 0.0231 \\
0.5739 & 0.4676 & -5.3282 & 0.0436 \\
-0.5050 & 0.0113 & 0.6895 & 0.0065 \\
2.8348 & -0.4097 & 4.4585 & 0.4737
\end{array}\right] \\
& \Delta=\left[\begin{array}{llll}
-9.1065 & -40.4296 & -1.0067 & -87.5736
\end{array}\right]^{\mathrm{T}}
\end{aligned}
$$
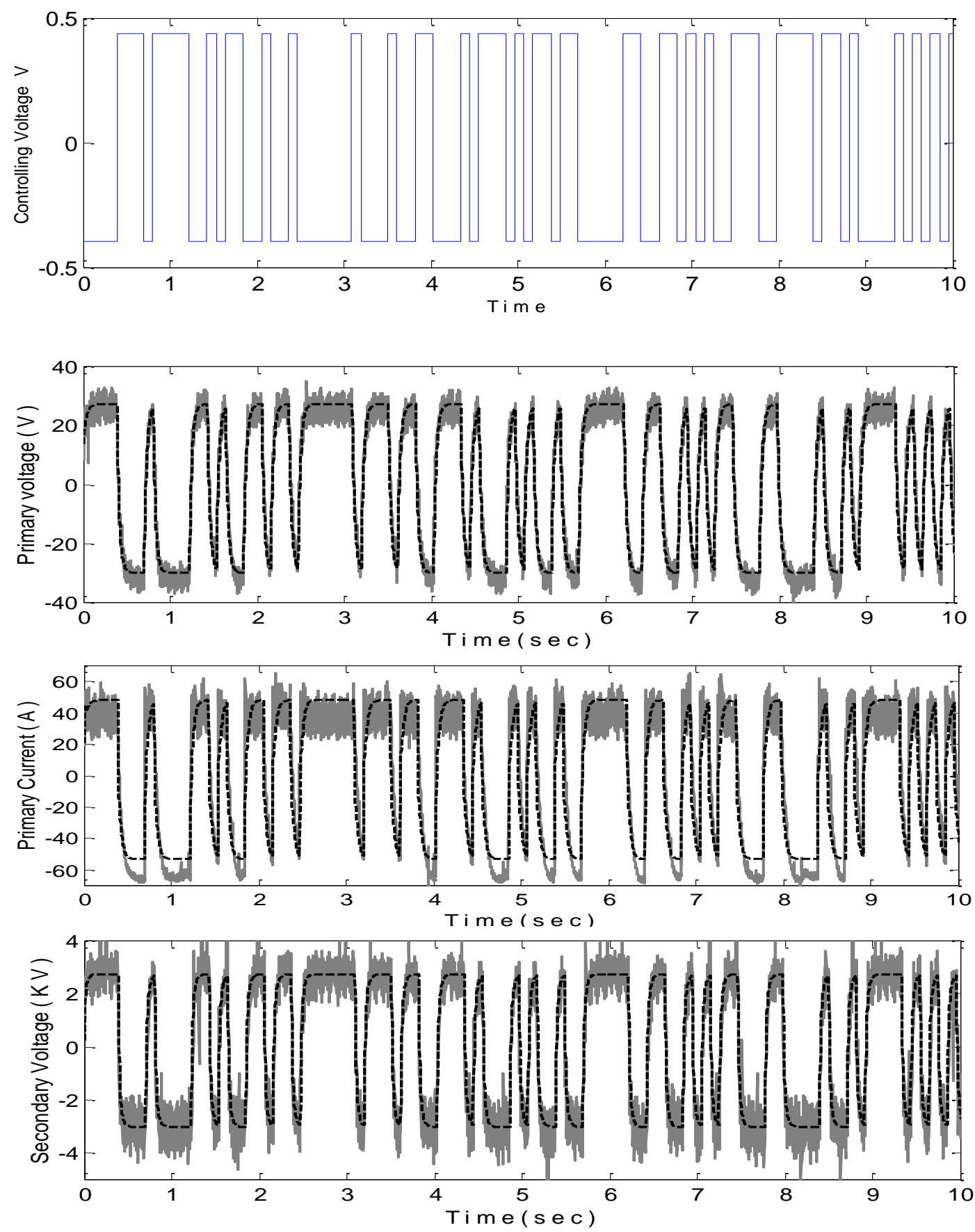


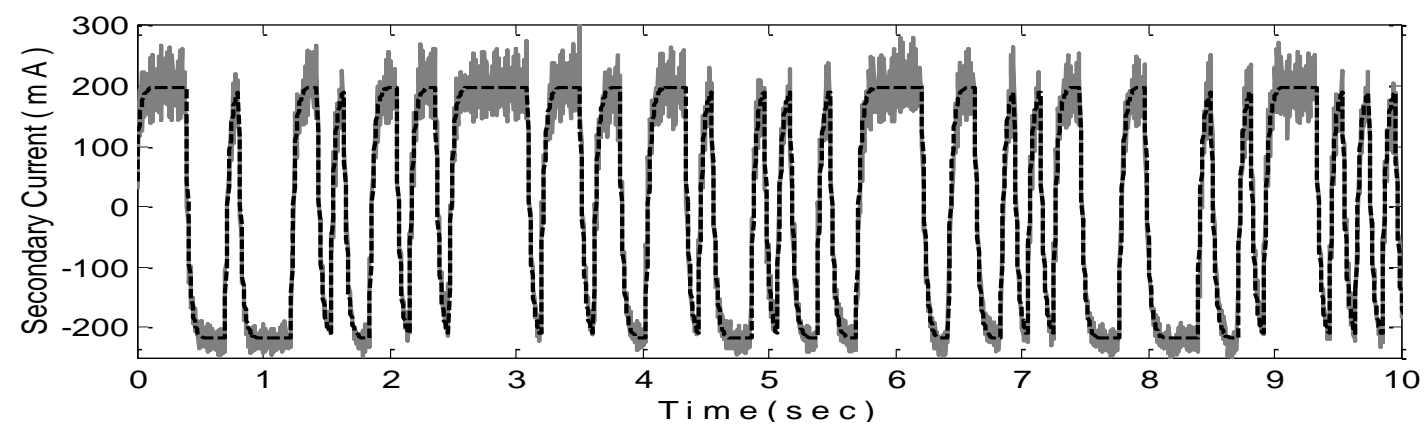

Fig. 3. Identified model assessment

- - - identified model output — real system output

\section{Optimal PI Control Design}

In designing an optimal control system a rule is needed for determining the present control decision, subject to certain constraints, so as to minimize some measure of the deviation from ideal behavior. That measure is usually provided by the chosen performance index, which is a function whose value is considered to be an indication of how well the actual performance of the system matches the desired performance. In most cases, the behavior of a system is optimized by choosing the control input $u_{k}$ in such a way that the performance index is minimized [22]. Except for special cases, the optimal control problem may be so complicated for an analytical solution that a computational solution has to be obtained.

The control system designed here includes state feedback and an integrator in the closed loop. Design variables are gain constant $\mathrm{f}_{\mathrm{I}}$ and feedback gain matrix $F$. In solving this design problem, define the input and state variables as given in equations (11) and (12). The secondary current $\left(I_{2}\right)$ is considered the output of the system. The desired secondary current is considered the reference input $r$.

Now, define the following equations for the PI controller:

$$
\begin{aligned}
& v_{k}=v_{k-1}+r_{k}-y_{k} \\
& u_{k}=F X_{k}+f_{I} v_{k} \\
& F=\left[\begin{array}{llll}
f_{1} & f_{2} & f_{3} & f_{4}
\end{array}\right]
\end{aligned}
$$

Since

$$
\begin{aligned}
& v_{k+1}=v_{k}+r_{k+1}-y_{k+1} \\
& v_{k+1}=v_{k}+r_{k+1}-\Theta\left[\Phi X_{k}+\Delta u_{k}\right] \\
& v_{k+1}=-\Theta \Phi X_{k}+v_{k}-\Theta \Delta u_{k}+r_{k+1}
\end{aligned}
$$

Now, combine equations (15) and (18), we obtain:

$$
\left[\begin{array}{l}
X_{k+1} \\
V_{k+1}
\end{array}\right]=\left[\begin{array}{cc}
\Phi & 0 \\
-\Theta \Phi & 1
\end{array}\right]\left[\begin{array}{l}
X_{k} \\
v_{k}
\end{array}\right]+\left[\begin{array}{c}
\Delta \\
-\Theta \Delta
\end{array}\right] u_{k}+\left[\begin{array}{l}
0 \\
1
\end{array}\right] r_{k+1}
$$


Define

$\Gamma=\left[\begin{array}{cc}\Phi & 0 \\ -\Theta \Phi & 1\end{array}\right], \quad \Omega=\left[\begin{array}{c}\Delta \\ -\Theta \Delta\end{array}\right], \quad Y_{k}=\left[\begin{array}{l}X_{k} \\ v_{k}\end{array}\right] \quad L=\left[\begin{array}{l}0 \\ 1\end{array}\right]$

Then,

$Y_{k+1}=\Gamma Y_{k}+\Omega u_{k}+L v_{k+1}$

Minimizing the quadratic performance index $J$, we obtain the optimal controller gain matrix $F$ and constant $f_{l}$.

$$
J=\sum_{k=0}^{\infty}\left(Y_{k}^{T} Q Y_{k}+u_{k} R u_{k}\right)
$$

The solution of equation (21) subject to equation (20) by using dynamic programming procedure gives the following proportional plus integral control law:

$$
u_{k}=F_{P I} Y_{k}
$$

Where $F_{P I}=\left[F-f_{I}\right]$

The traditional way to select the weighting matrix $Q$ and scalar $R$ is to use trial and error method. Many simulation studies have been done in time domain with different weighting matrices to choose the ones that provide desired performance. Because of the complexity, $Q$ is commonly chosen as diagonal matrix.

Step response testes are performed with different choices of the matrices $Q$ and $R$. A good step response should give a compromise of a low rise time (time required for the response to rise from $0 \%$ to $100 \%$ of its final value), a low maximum overshoot (maximum peak value of the response curve), a low settling time (time required for the response curve to reach and stay within a range about the final value). Acceptable response was achieved with $Q \operatorname{diag}(400,1,1,1,1)$ and $R=1$.

\section{Experimental Results of High Voltage Unit with PI Optimal Control}

Experimental test results on the real high voltage unit of the cement kiln ESP filter are presented to show the effectiveness of the optimal PI controller developed in this paper. The operating conditions of the electrostatic precipitator during the experiments as recorded from the central control room are as follows:

- EP1 inlet temperature $=234{ }^{\circ} \mathrm{C}$

- EP1 outlet temperature $=218^{\circ} \mathrm{C}$

- EP2 inlet temperature $=242{ }^{0} \mathrm{C}$

- EP2 outlet temperature $=224{ }^{0} \mathrm{C}$

- Temperature of smoke chamber $236{ }^{\circ} \mathrm{C}$

- South fan 48 A, damper opened $80 \%$

- North fan 48 A, damper opened $90 \%$

- Kiln feed 19 Liter/sec, moisture content $37.6 \%$

- HV units readings during the experiment were as follows EP1:

- Inlet: TR1 Out of service, TR2 $44 \mathrm{KV} 65 \mathrm{~mA}$

- Outlet: TR3 Out of service, TR4 30 KV 440 mA 
EP2:

- Inlet: TR1 37 KV 340 mA, TR2 38 KV 480 mA

- Outlet: TR3 19 KV 420 mA

Fig. 4 shows the system response to the step change in the reference input. The primary voltage, primary current, secondary voltage, and secondary current are shown in each test. It is evident that the response of the system is acceptable. Overshoot, settling time and rise time are low. Primary current and secondary current are not highly fluctuating. Fig. 5 shows the system response to a step change of $500 \mathrm{~mA}$ in the reference input.

An additional experimental test is performed on the high voltage unit by using the optimal controller. A step of reference input of $50 \mathrm{~mA}$ is applied to the system from rest and allowed to be increased by $50 \mathrm{~mA}$ for nine times each 200 sampling intervals till it reaches $500 \mathrm{~mA}$ then allowed to be decreased by $50 \mathrm{~mA}$ for ten times till it reaches the initial value. The response of the system to this input was recorded and plotted as shown in Fig. 6. The system satisfactorily follows the changes in the reference input.
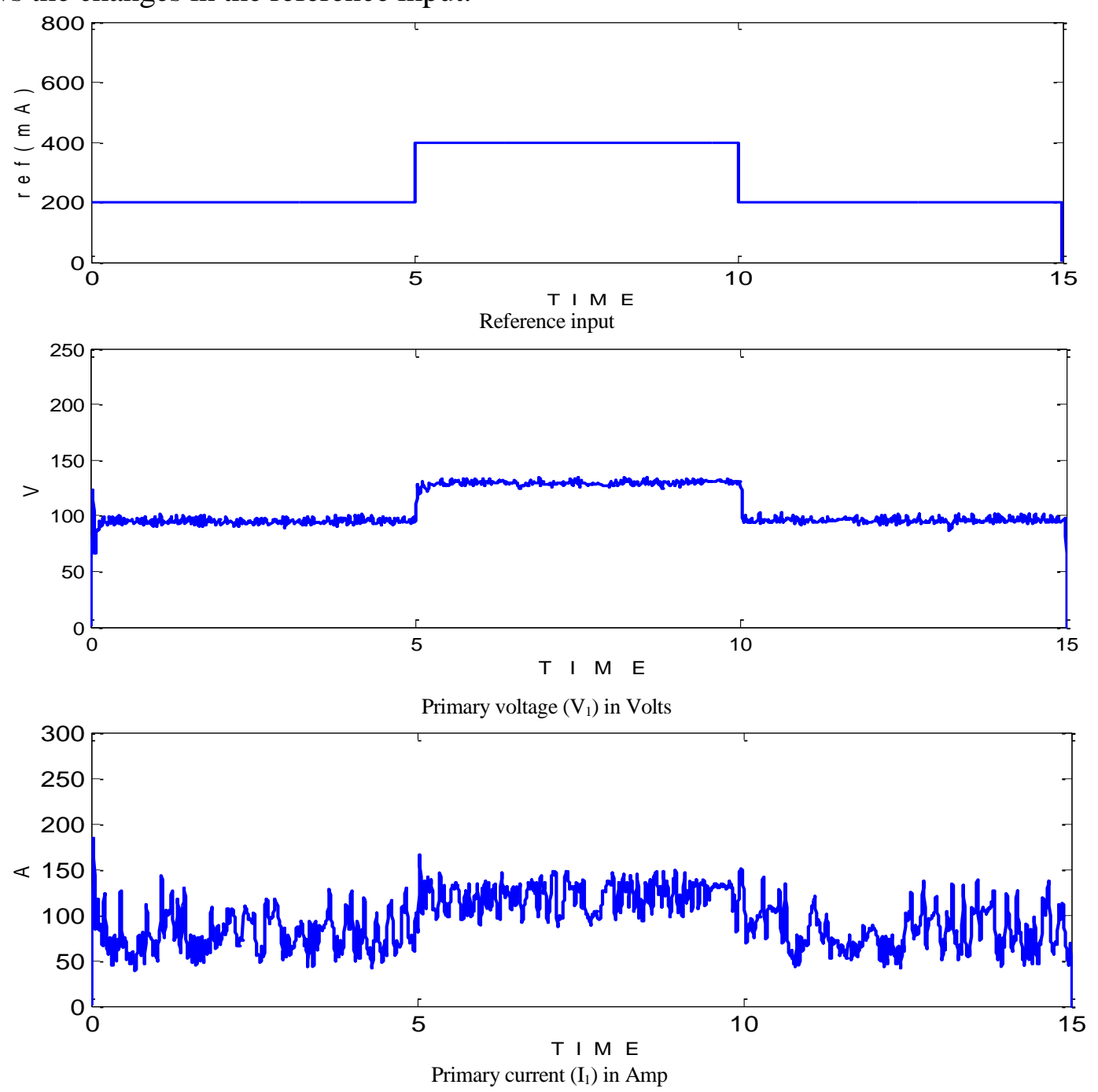

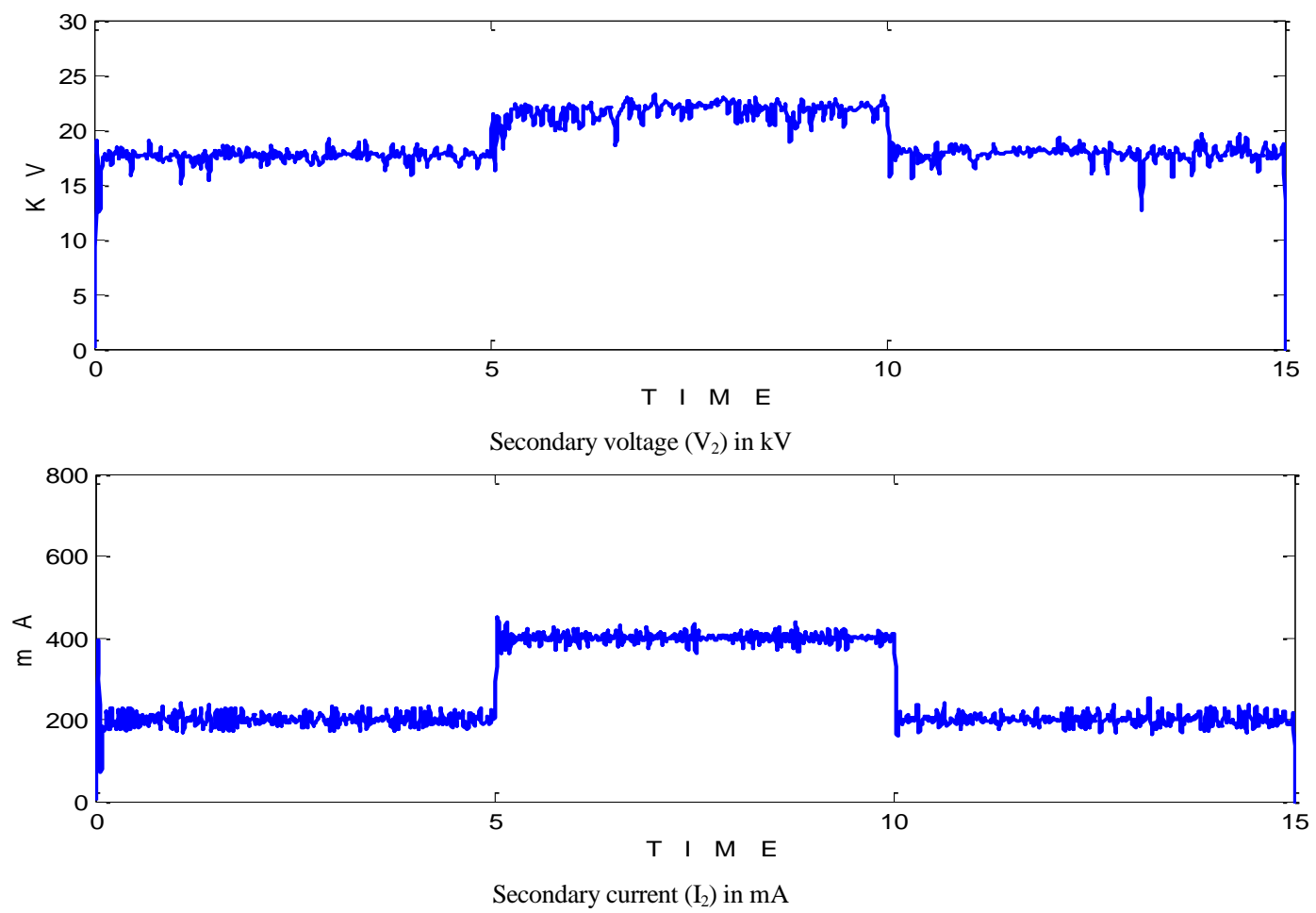

Fig. 4. System response to step changes in reference input
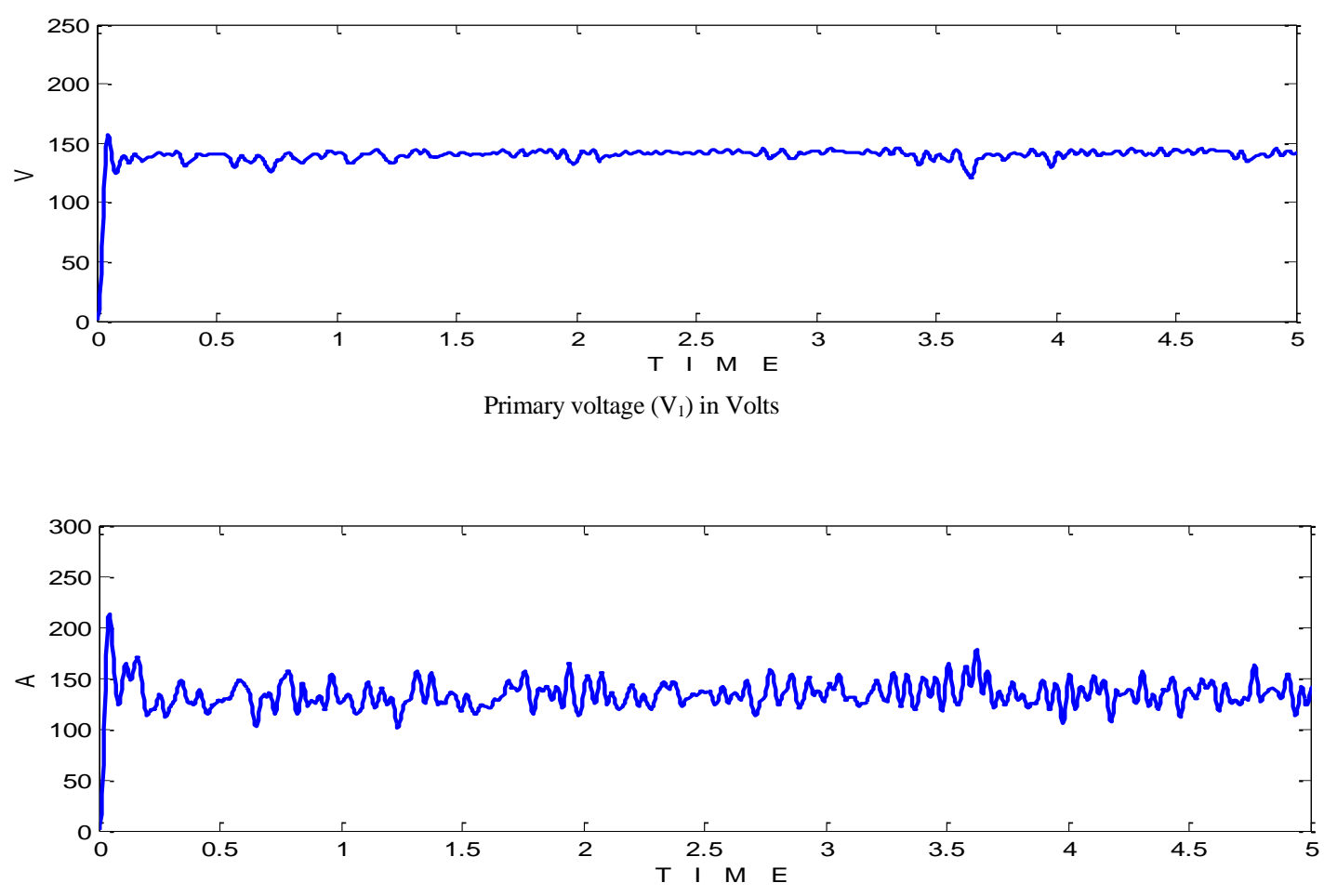

Primary current $\left(I_{1}\right)$ in Amp 


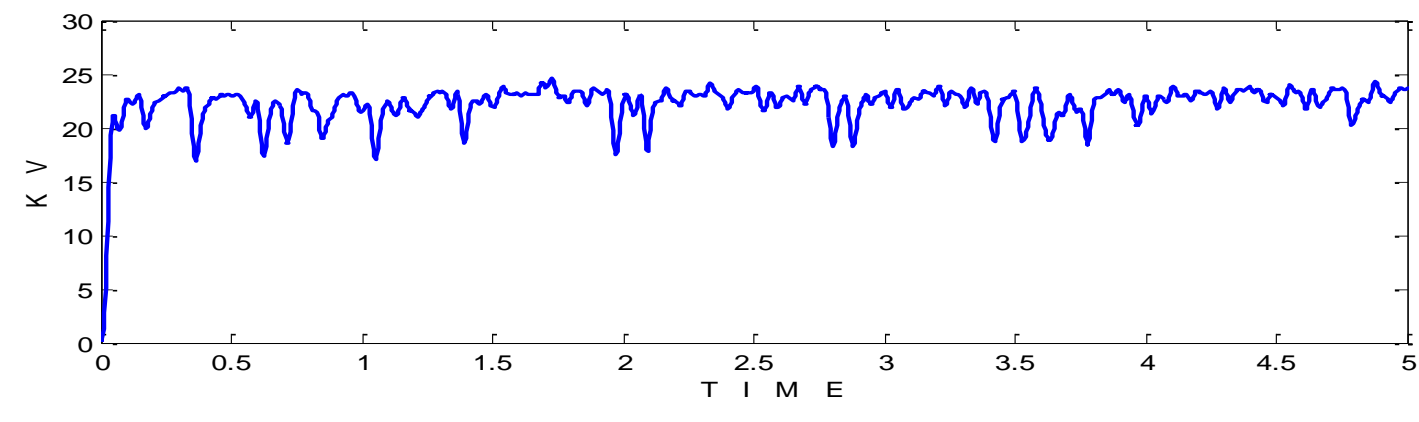

Secondary voltage $\left(\mathrm{V}_{2}\right)$ in $\mathrm{kV}$

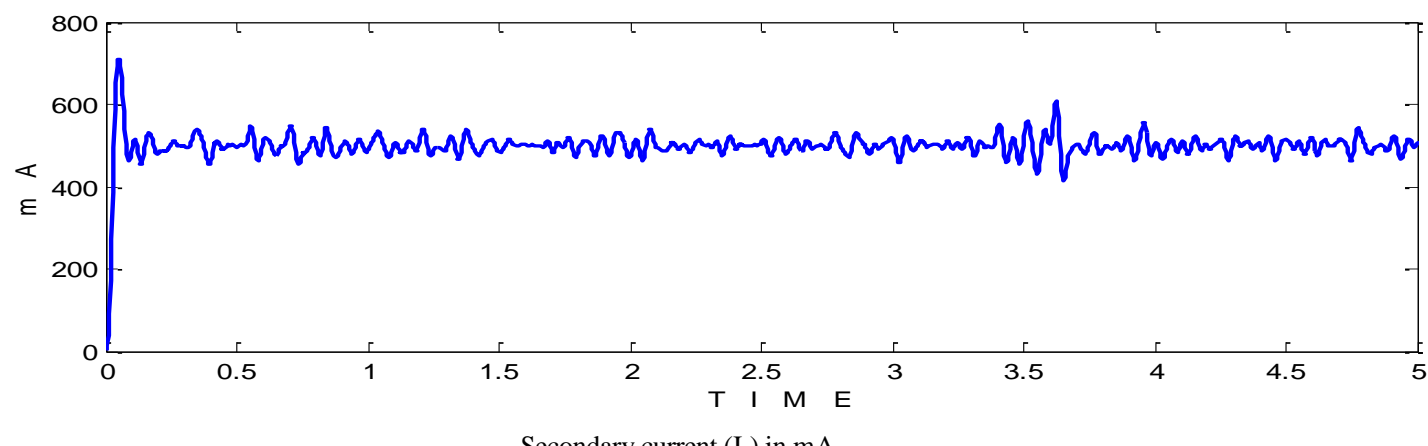

Secondary current $\left(I_{2}\right)$ in $\mathrm{mA}$

Fig. 5. System response to a step of $500 \mathrm{~mA}$
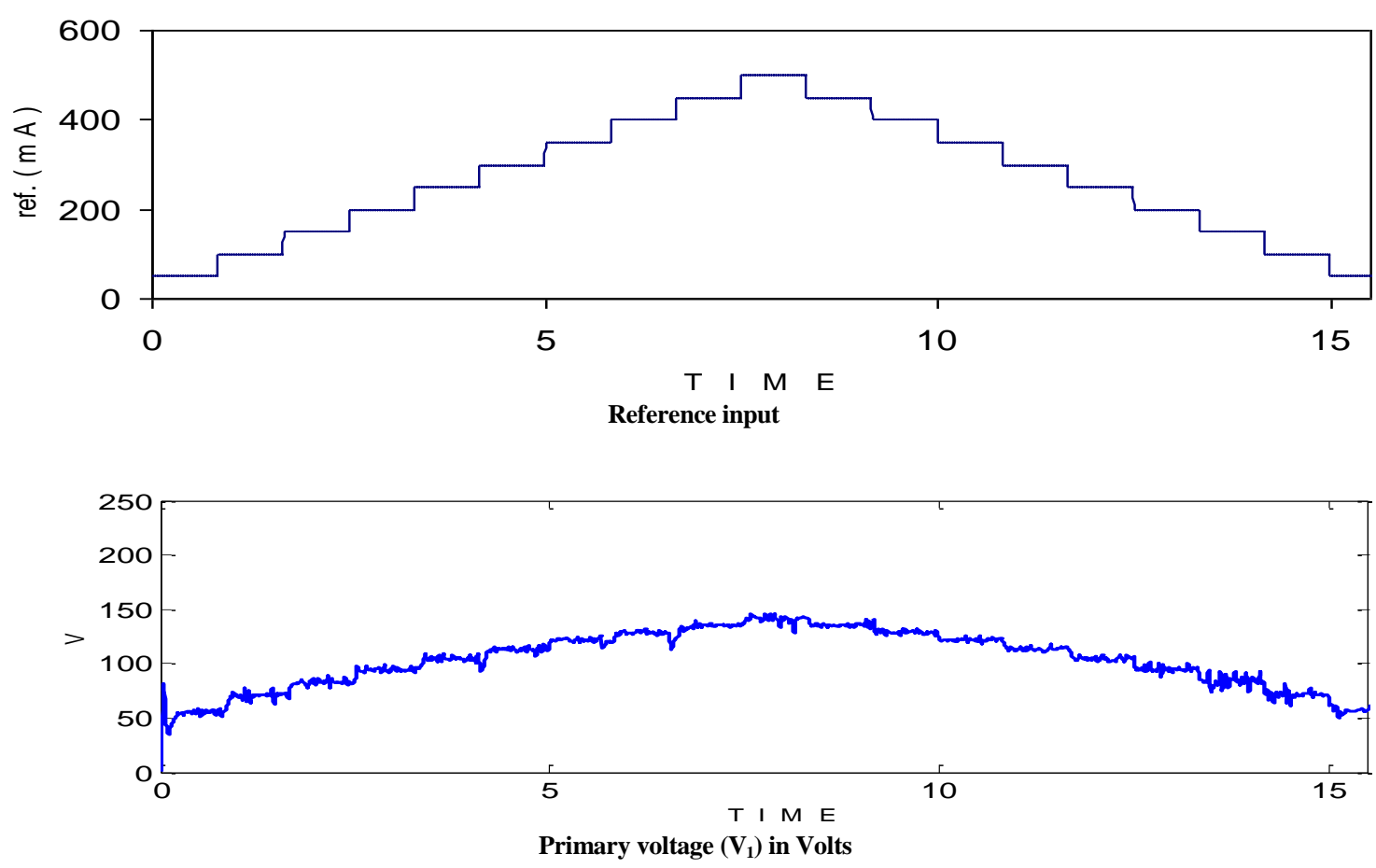

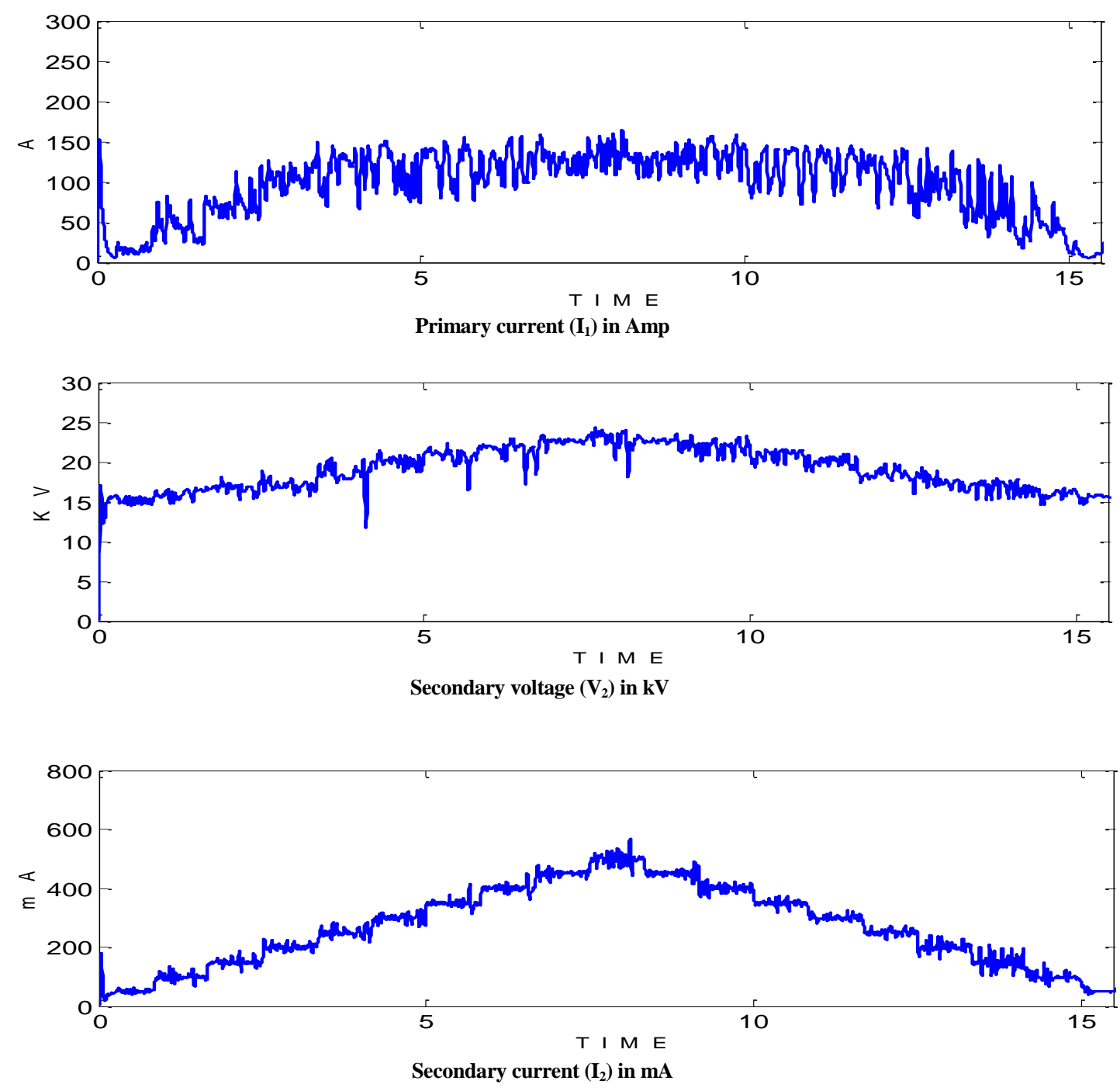

Fig. 6. System response to variable step input

\section{Conclusions}

The paper has presented practical applications of recursive least-squares identification and optimal PI control design of a real ESP filter of a cement kiln in a large cement factory. Data are collected from the ESP by specially designed electronic interface system. Comparison made between the identified model and the real system has proved model validity. An optimal PI controlled has been designed on the basis of the identified model by using dynamic programming procedure. The PI controller has been implemented on the real ESP filter through a computer interfaced system. Closed loop test results have been presented to show the effectiveness of the optimal PI controller.

\section{Acknowledgement}

The authors are grateful for all top management and engineers in the National Cement Company and ASEC Environmental Protection Company who have actively helped and facilitated performing the practical tests and works described in this paper.

\section{References}

[1] McLean, K.J., "Electrostatic precipitators", Proc. IEE, Vol. 135, Pt. A, July 1988, pp. 347-361.

[2] Rose, H.E. and Wood, A.J., "An Introduction to Electrostatic Precipitation", London, Constable, $2^{\text {nd }}$ ed., 1996. 
[3] Mizuno, A., "Electrostatic Precipitation", IEEE Trans. Dielectrics and Electrical Insulation, Vol. 75, October 2000, pp. 615-624.

[4] Bradley, A., Chen, B., Jackson, K., Moore, R. and Baloga, S., "Multi-pollutant control for the Portland cement industry," Proc. IEEE-IAS/PCA 53rd Cement Industry Technical Conference, 2011, pp. 1-13.

[5] $\mathrm{Wu}, \mathrm{K} . \mathrm{X}$. and Zheng, Y., "The analysis and design of steel plant electrostatic precipitator control system based on IFIX measuring technology and mechatronics automation," Proc. Int. Conf. ICMTMA'09, Vol. 1, 2009, pp. 898-900.

[6] Yamamoto, T., Maeda, S., Ehara, Y. and Kawakami, H., "Development of EHDAssisted Plasma Electrostatic Precipitator", IEEE Transactions on Industry Applications, Vol. 49 (2), 2013, pp. 672 - 678.

[7] Fischer, T., Grass, N., Zouzou, N., Dascalescu, L., Greil, R. and Hopf, N., "Smart Home Precipitator for biomass-furnaces: Design considerations on a small scale electrostatic precipitator," IEEE Industry Applications Society Annual Meeting (IAS), 2012, pp. 1-5.

[8] Clements, J.S., Johansen, M.R., Lowder, M.L., Thompson, S.M., Williams, B.S., Calle, C.I., Cox, N.D. and M. D. Hogue, "Development of an electrostatic precipitator to remove Martian atmospheric dust from ISRU gas intakes during planetary exploration missions," IEEE Industry Applications Society Annual Meeting (IAS), 2011 pp. 1-8.

[9] Russell-Jones, A. and Weinmann, S. F., "Development of microprocessor control systems for electrostatic precipitators", Current Environmental Applications of Electrostatic precipitators, IEE Colloquium, London, June 1991, pp. 5/1-5/3.

[10] Durga Prasad, N.V.P.R., "Automatic control and management of electrostatic precipitator", IEEE Trans. Industry Applications, Vol. 35 (3), May-June 1999, pp.561567.

[11] Feshara, H.F., "Improving the performance of an electrostatic precipitator using an intelligent digital controller", M. Sc. Thesis, University of Helwan, 2006.

[12] Abdalla, O.H., Sharaf, S.M. and Feshara, H.F., "Computer interface System for a High Voltage Unit of an Industrial Electrostatic Precipitator" Proc. International Conference on Communications, Computer and Power, ICCCP09, Sultan Qaboos University, Muscat, Oman, 15-18 February 2009, pp. 305-309.

[13] Astrom K.H. and Eykhoff, P., "System identification - a survey", Automatica, 7, 1971, pp. 123-126.

[14] Franklin, G.F. and Powell, J.D. "Digital control of dynamic systems", Addison-Wesley, 1980.

[15] Miao, B., Zane, R. and Maksimovic, D. "System identification of power converters with digital control through cross-correlation methods", IEEE Trans. on Power Electronics, Vol. 20 (5), September 2005, pp. 1093-1099.

[16] Sharaf S.M. and Serag, A.M. "Practical identification and PI optimal controller of a laboratory drive system", Int. J. Control, Vol. 6 (2), 1995, pp. 511-526.

[17] Abdalla, O.H. and Walker, P.A.W., "Identification and optimal output control of a laboratory power system”, Proc. IEE, Pt D, Vol. 127 (6), 1980, pp. 237-244.

[18] Sharaf, M.M. and Hogg, B.W. "Identification and control of a laboratory model turbogenerator", Int. j. Control, Vol. 31, 1981, pp. 723-739.

[19] Brogan, W.L. "Modern Control Theory", Quantum Publishers, Inc., 1974.

[20] Sandoz, D.J. and Swanick, B.H. "A recursive least squares approach to the on-line adaptive control problem", Int. j. Control, Vol. 16, pp. 243-260, 1972.

[21] Ljung, L. and Glad, T., "Modelling of dynamic systems", Prentice-Hall, 1994.

Ogata, K., "Discrete-time control systems", Prentice-Hall International, Inc., 1995. 